\title{
Influence of cytotoxic $T$ lymphocyte-associated antigen 4 polymorphisms on the outcomes of hepatitis $B$ virus infection
}

\author{
MAN CHEN, YING CHANG, FENG TANG, QIONG-HUI XIE, \\ JIN LI, HONG YANG, XING-XING HE and JU-SHENG LIN
}

Institute of Liver Diseases, Tongji Hospital of Tongji Medical College, Huazhong University of Science and Technology, Wuhan, Hubei 430030, P.R. China

Received July 2, 2013; Accepted October 31, 2013

DOI: $10.3892 / \mathrm{mmr} .2013 .1825$

\begin{abstract}
Cytotoxic T lymphocyte-associated antigen 4 (CTLA-4) regulates T-cell activation and Th1/Th2 cytokine production and is involved in the immune response against Hepatitis B virus (HBV) infection. To detect the association of the CTLA-4 gene polymorphisms with susceptibility to HBV infection a hospital-based case-control study was conducted. A total of 1,119 unrelated individuals were recruited. The CTLA-4 variants rs5742909, rs231775 and rs3087243 were genotyped via the TaqMan method in this cohort. A comparison with a chronic active hepatitis $\mathrm{B}$ group revealed that the SNP rs231775 exhibited significant susceptibility to HBV progression, with the highest odds ratio (OR) reaching 1.659 and $\mathrm{P}=0.009-0.049$. Although an HBV clearance group was used as a control, results of the present study demonstrated an association of rs5742909 with viral persistence [OR=1.694, $95 \%$ confidence intervals $(\mathrm{CI})=1.124-2.553$ and $\mathrm{P}=0.012]$. Subsequent analyses revealed risk haplotypes (C-A-A and T-A-G, for which the highest OR reached 1.865) compared with the protective haplotype C-G-G. Therefore, SNPs in the CTLA-4 gene may be associated with HBV progression and viral persistence which is consistent with its emerging role in the $\mathrm{T}$ regulatory cells in the pathogenesis of disease.
\end{abstract}

\section{Introduction}

Hepatitis B virus (HBV) infection is a worldwide health problem and more than two billion people have been infected with HBV (1). Although many individuals eventually achieve a state of non-replicative infection, the prolonged immunological response to infection leads to the development of cirrhosis, liver failure or hepatocellular carcinoma (HCC) in

Correspondence to: Dr Ju-Sheng Lin or Dr Xing-Xing He, Institute of Liver Diseases, Tongji Hospital, no. 1095 Jie-Fang Avenue, Wuhan, Hubei 430030, P.R. China

E-mail: jslin@tjh.tjmu.edu.cn

E-mail: xxhe@tjh.tjmu.edu.cn

Key words: CTLA4, hepatitis B, polymorphisms, haplotype up to $40 \%$ of patients (2). In China, 120 million people are HBV chronic carriers, and $50-80 \%$ of cirrhosis patients are infected with HBV (1). Persistent HBV infection has been considered a multifactorial and polygenic disequilibrium among viral, environmental and host genetic components (3). Single-nucleotide polymorphisms (SNPs) are the most abundant form of DNA variation in the human genome and contribute to human phenotypic differences (4). A number of studies have demonstrated the role of host genetic factors and their interactions with environmental factors leading to various outcomes following HBV infection (5-8). Understanding the key factors that influence the clinical outcomes of HBV infection is crucial for early diagnosis and optimal treatment (9).

Cytotoxic T lymphocyte-associated antigen 4 (CTLA-4), mapped to chromosome $2 \mathrm{q} 33$ (10) and expressed in the activated and regulatory $\mathrm{T}$ cells, regulates $\mathrm{T}$-cell activation and tolerance (11), Th1/Th2 differentiation and cytokine production (12) following B7 engagement. CTLA-4 has been established as a significant negative regulator of T-cell responses, leading to the preservation of $\mathrm{T}$-cell homeostasis (13). Previously, it was reported that CTLA-4 may downregulate the immune response strength of tumor immunity (14), allergy (15), autoimmune disease (16), infection (17) and vaccination (18). In addition to inhibiting T-cell activation and proliferation, CTLA-4 may also induce Fas-independent apoptosis of activated T cells (19). Cytokines including TNF- $\alpha$ and IFN- $\beta$ are critical, not only for viral clearance, but also for the immunopathogenesis of HBV infection $(20,21)$. Therefore, the interaction of CTLA-4 with B7 molecules in regulating T-cell activation and Th1/Th2 cytokine production is involved in the immune response against HBV infection (22).

SNPs in CTLA-4 have been connected to the susceptibility to autoimmune disease and various types of cancer (23). Findings from recent studies have demonstrated that CTLA-4 gene polymorphisms may affect the susceptibility and chronicity of the disease in patients with HBV infection (24-29). However, the results remain controversial and whether CTLA-4 gene polymorphisms are associated with the status of HBV infection including chronic carriers and cirrhosis, and hepatitis $\mathrm{B}$ e antigen ( $\mathrm{HBeAg}$ ) positivity in the infected patients remains to be determined. In addition, the criteria for the control and case groups were not completely equal among these studies. Thus, whether there is an association between 
CTLA-4 genetic variations and HBV infection in the Chinese population using equal criteria remains to be clarified. In the present study, three SNPs were selected from the CTLA-4 gene: rs5742909 (-318 C/T) at the promoter region, rs231775 (+49 A/G), a non-synonymous at the exon 1 and rs3087243 (+6230 $\mathrm{G} / \mathrm{A}$ ) at the downstream in the $3^{\prime}$ untranslated region (UTR). The three polymorphisms were genotyped in a hospital-based case-control study, including 1,119 unrelated Han Chinese subjects from the Hubei province (Central China).

\section{Materials and methods}

Study subjects. In this hospital-based case-control study, a total of 1,119 unrelated Han Chinese individuals were recruited from Tongji Hospital and Union Hospital, Wuhan, China, between July 2007 and September 2009. All the subjects were divided into four groups: i) the HBV clearance group (clear); ii) the chronic active hepatitis B group (CHB); iii) the HBV-related liver cirrhosis group (LC) and iv) the HBV-related hepatocellular carcinoma group (HCC). The diagnostic criteria for study inclusion were described previously (6). Moreover, patients with positive laboratory tests for human immunodeficiency virus (HIV), alcoholic liver disease, suspected autoimmune diseases or schistosomiasis were excluded from the study.

All the study subjects were of unrelated ethnic background, Han Chinese who lived in Wuhan or the surrounding region. Informed consent was obtained from each participant for study enrollment. An information questionnaire was used and the demographic information included gender, age and place of origin. The study was approved by the local Research Ethics Committee at the Tongji Hospital, Huazhong University of Science and Technology in accordance with the principle of the Helsinki Declaration II.

DNA isolation and genotyping. Genomic DNA was isolated from the peripheral whole blood using a TIANamp blood DNA kit [Tiangen Biotech (Beijing) Co., Ltd., Beijing, China]. The concentration and purity of the DNA were determined with a NanoDrop spectrophotometer (Thermo Fisher Scientific, Wilimington, DE, USA), then diluted to a final concentration of $8 \mathrm{ng} / \mathrm{ml}$ and distributed to a 96-well plate. Genotyping of genetic polymorphisms was performed via the TaqMan method according to the instructions of TaqMan ${ }^{\circledR} \mathrm{R}$ SNP Genotyping Assays (Applied Biosystems, Carlsbad, CA, USA). To detect the three SNPs (rs5742909, rs231775 and rs3087243), TaqMan ${ }^{\circledR} \mathrm{R}$ MGB Probes and the primers for PCR amplification (Table I) were customized. The probes were labeled with FAM and VIC dyes to denote the two different alleles, respectively, and the allelic category was measured automatically using the Sequence Detection System 2.3 software (Applied Biosystems) according to the intensity of the VIC and FAM dyes.

Statistical analysis. A statistical analysis was conducted using Arlequin 3.5 (30), haploview 4.2 (Cambridge, MA, USA) and SPPS 17.0 (SPSS, Inc., Chicago, IL, USA) softwares. The Hardy-Weinberg equilibrium was tested separately for cases and controls by Arlequin 3.5. Linkage disequilibrium (LD) and haplotypes were assessed by the haploview 4.2 software. Genotypic analyses included allele, dominant, recessive and additive genetic models. The $\chi^{2}$ test or Fisher's-exact test was applied to a row-by-column contingency table in the four genetic models. Age- and gender-adjusted odds ratios (ORs) and $95 \%$ confidence intervals (CIs) were calculated on the basis of the unconditional binary logistic regression model. The strength of association between the genotypes or alleles and HBV infection was estimated by the SPSS17.0. ORs and $95 \%$ CIs were calculated using the major allele as a reference. All the tests were two sided with $\mathrm{P}<0.05$ considered to indicate a statistically significant difference.

\section{Results}

Clinical and demographic characteristics. The clinical and demographic characteristics of the case-control study included gender, age, drinking habits, serum $\alpha$-fetoprotein level, serum total bilirubin level, alanine transaminase, HBV-DNA load and serum markers of hepatitis B virus (Table II). Although an effort was made to obtain a good match on the age and gender, there were more male subjects in the three HBV infection groups $(\mathrm{CHB}+\mathrm{LC}+\mathrm{HCC}$; average $78.7 \%)$ compared with those in the clear group $(59.3 \%, \mathrm{P}<0.05)$. The individuals in the $\mathrm{CHB}$ group were younger compared with those in the LC and HCC groups $(\mathrm{P}<0.001)$. However, populations in the LC and HCC groups demonstrated no significant difference with the clear group with regard to age $(\mathrm{P}>0.05)$. No significant difference was observed in the percentage of hepatitis $\mathrm{B}$ e antigen (HBeAg)-positive $(\mathrm{P}>0.05)$ between the patients in the LC group (11.74\%) and those in the HCC group (10.24\%). In addition, there was more alcohol consumption in patients $(\mathrm{P}<0.05)$ with the LC $(29.11 \%)$ and HCC $(34.19 \%)$ groups compared with those in the clear (13.17\%) and CHB (18.63\%) groups. The difference in the alcohol consumption status may be due to the limited number of drinkers within the Chinese female population.

Hardy-Weinberg equilibrium test. Hardy-Weinberg equilibrium was estimated by the Fisher's exact test via Arlequin 3.5 software. The allele and genotype distributions are shown in Tables III and IV. No significant difference was revealed between the observed and expected frequencies of each genotype in these groups $(\mathrm{P}>0.05)$. All the genotype distributions of the three SNPs (rs231775, rs5742909 and rs3087243) conformed to the Hardy-Weinberg equilibrium $(\mathrm{P}>0.05)$ in all the groups, making it suitable for subsequent statistical analysis.

Associations of the CTLA-4 polymorphisms with HBV progression. To investigate which genotypic models were significantly associated with various outcomes, a comparison of the four models was conducted (multiplicative, additive, dominant and recessive models) in the Hubei Han Chinese population (data not shown). The best-fitting genotypic effect of the three SNPs (rs5742909, rs231775, rs3087243) was observed in the dominant model (Table III). Distributions of the CTLA-4 polymorphisms in the case and control groups are summarized in Tables III and IV. At the SNP site rs231775, the significant difference in allele distribution was observed only between the CHB and LC groups ( $\mathrm{P}=1.53 * 10 \mathrm{E} 4)$. Following adjustment for age and gender and analysis by unconditional binary logistic 
Table I. TaqMan ${ }^{\circledR}$ probe and primer for three SNPs.

\begin{tabular}{lccc}
\hline SNP (NCBI reference no.) & rs5742909 & \multicolumn{1}{c}{ rs231775 } & rs3087243 \\
\hline Forward primer & Commercialized & GCACAAGGCTCAGCTGAAC & CCATCCTCTTTCCTTTTGATTTCTTCAC \\
Reverse primer & Commercialized & CAGAAGACAGGGATGAAGAGAAGAA & TGTGTTAAACAGCATGCCAATTGATT \\
MGB probe 1 & Commercialized & VIC-CCAGGTCCTGGTAGCCA-MGB & VIC-TCTGTGTTAACCCATGTTATA-MGB \\
MGB probe 2 & Commercialized & FAM-CAGGTCCTGGCAGCCA-MGB & FAM-TGTGTTAACCCACGTTATA-MGB \\
\hline
\end{tabular}

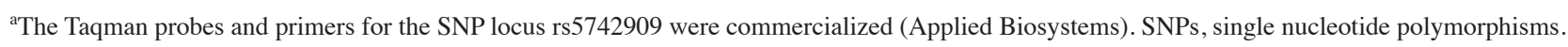

Table II. Clinical characteristics of the study subjects.

\begin{tabular}{|c|c|c|c|c|}
\hline Characteristics & Clear, $n=205$ & $\mathrm{CHB}, \mathrm{n}=467$ & $\mathrm{LC}, \mathrm{n}=213$ & $\mathrm{HCC}, \mathrm{n}=234$ \\
\hline \multicolumn{5}{|l|}{ Gender, no. (\%) } \\
\hline Male & $121(59.3)$ & $343(73.4)$ & $184(86.4)$ & $192(82.1)$ \\
\hline Female & $83(40.7)$ & $124(26.6)$ & $29(13.6)$ & $42(17.9)$ \\
\hline Age in years, mean $\pm \mathrm{SD}$ & $48.85 \pm 12.52$ & $35.42 \pm 12.89$ & $46.21 \pm 10.83$ & $47.84 \pm 13.23$ \\
\hline Drinkers, no. $(\%)$ & $27(13.17)$ & $87(18.63)$ & $62(29.11)$ & $80(34.19)$ \\
\hline HBsAg & All $^{-}$ & $\mathrm{All}^{+}$ & $\mathrm{All}^{+}$ & $\mathrm{All}^{+}$ \\
\hline Anti-HBs IgG & $\mathrm{All}^{+}$ & All & All ${ }^{-}$ & All $^{-}$ \\
\hline HBeAg-positive, no. (\%) & All $^{-}$ & $94(20.13)$ & $25(11.74)$ & $24(10.24)$ \\
\hline Anti-HBc IgG & $\mathrm{All}^{+}$ & $\mathrm{All}^{+}$ & $\mathrm{All}^{+}$ & $\mathrm{All}^{+}$ \\
\hline Family history, no. (\%) & No & 69 (14.78) & $27(12.68)$ & $47(20.09)$ \\
\hline ALT, U/1 & No & $420.33 \pm 399.23$ & $110.46 \pm 115.24$ & $90.63 \pm 75.17$ \\
\hline TBil, mmol/l & No & $180.23 \pm 171.45$ & $132.28 \pm 120.86$ & $64.36 \pm 60.74$ \\
\hline HBV-DNA, copy/ml & No & $(3.05 \pm 3.67) \mathrm{E} 7$ & $(2.34 \pm 4.02) \mathrm{E} 6$ & $(5.59 \pm 2.34) \mathrm{E} 6$ \\
\hline
\end{tabular}

Total number for gender was not in accordance with the sum of each group as not all of the information was completelely collected. No, non-detected. Drinkers, alcohol consumption of $40 \mathrm{~g} /$ week, which included occasional and daily drinkers. Clear, HBV clearance group; CHB, chronic active hepatitis B group; LC, HBV-related liver cirrhosis group; HCC, HBV-related hepatocellular carcinoma group. HbsAg, hepatitis B antigens; ALT, alanine transaminase; TBil, total bilirubin level; HBV, hepatitis B virus.

Table III. Association of three SNPs (rs5742909, rs231775 and rs3087243) with HBV infection progression and clearance in the Han Chinese populations (dominant model).

Dominant model

\begin{tabular}{|c|c|c|c|c|c|c|}
\hline \multirow[b]{2}{*}{ SNPs } & \multirow[b]{2}{*}{ Sample } & \multirow[b]{2}{*}{ Allele distribution } & \multirow[b]{2}{*}{$P$-value ${ }^{a}$} & \multirow[b]{2}{*}{ Genotypes } & \\
\hline & & & & & P-value & OR $(95 \% \mathrm{CI})^{\mathrm{b}}$ \\
\hline \multirow[t]{3}{*}{ rs5742909 } & $(-318 \mathrm{C}>\mathrm{T})$ & $\mathrm{C} / \mathrm{T}$ & & $\mathrm{CC} / \mathrm{CT} / \mathrm{TT}$ & CC vs. CT+TT & $\mathrm{CC}$ vs. $\mathrm{CT}+\mathrm{TT}$ \\
\hline & Clear & $358 / 42$ & Ref. & $160 / 38 / 2$ & Ref. & Ref. \\
\hline & $\mathrm{CHB}+\mathrm{LC}$ & $1126 / 206$ & 0.013 & $478 / 170 / 18$ & 0.012 & $1.694(1.124-2.553)$ \\
\hline \multirow[t]{5}{*}{ rs231775 } & $(+49 A>G)$ & $\mathrm{A} / \mathrm{G}$ & & AA/GA/GG & GG vs. AG+AA & GG vs. AG+AA \\
\hline & $\mathrm{CH}$ & $320 / 610$ & Ref. & $53 / 214 / 198$ & Ref. & Ref. \\
\hline & LC & $189 / 229$ & $1.53 * 10 \mathrm{E} 4$ & $46 / 97 / 66$ & 0.009 & $1.659(1.137-2.421)$ \\
\hline & $\mathrm{HCC}$ & $184 / 284$ & 0.071 & $42 / 100 / 92$ & 0.537 & $1.119(0.782,1.602)$ \\
\hline & $\mathrm{HCC}+\mathrm{LC}$ & $373 / 513$ & 0.001 & $88 / 198 / 158$ & 0.049 & $1.353(1.001-1.829)$ \\
\hline \multirow[t]{5}{*}{ rs 3087243} & $(+6230 G>A)$ & $\mathrm{G} / \mathrm{A}$ & & GG/GA/AA & GG vs. GA+AA & GG vs. GA+AA \\
\hline & $\mathrm{CH}$ & $750 / 184$ & Ref. & $301 / 148 / 18$ & Ref. & Ref. \\
\hline & LC & $314 / 108$ & 0.015 & $121 / 72 / 18$ & 0.167 & $1.294(0.898-1.866)$ \\
\hline & $\mathrm{HCC}$ & $349 / 113$ & 0.041 & $134 / 81 / 16$ & 0.235 & $1.247(0.866-1.771)$ \\
\hline & $\mathrm{LC}+\mathrm{HCC}$ & $663 / 221$ & 0.007 & $255 / 153 / 34$ & 0.191 & $1.224(0.904-1.656)$ \\
\hline
\end{tabular}

Total number for the polymorphism was not in accordance with the sum of each genotype as not all the samples were successfully genotyped. ${ }^{\text {aP-values }}$ were obtained by the $\chi^{2}$ test. ${ }^{b}$ The P-values, odds ratios (ORs) and $95 \%$ confidence intervals (CIs) were calculated on the basis of the binary logistic regression analysis and adjusted for gender and age. Bold text denotes statistically significant differences. SNPs, single-nucleotide polymorphisms; HBV, hepatitis B virus. 
Table IV. Alleles and genotypes distribution of the three SNPs in the cases and controls.

\begin{tabular}{|c|c|c|c|c|}
\hline SNP ID & Clear & $\mathrm{CHB}$ & $\mathrm{LC}$ & $\mathrm{HCC}$ \\
\hline \multicolumn{5}{|l|}{ rs5742909 } \\
\hline $\mathrm{C}$ & $358(89.5)$ & $796(85.8)$ & $330(81.7)$ & $400(89.3)$ \\
\hline $\mathrm{T}$ & $42(10.5)$ & $132(14.2)$ & $74(18.3)$ & $48(10.7)$ \\
\hline $\mathrm{CC}$ & $160(80.0)$ & $342(73.7)$ & $136(67.3)$ & $176(78.6)$ \\
\hline $\mathrm{CT}$ & $38(19.0)$ & $112(24.1)$ & $58(28.7)$ & $48(21.4)$ \\
\hline $\mathrm{TT}$ & $2(1.0)$ & $10(2.2)$ & $8(4.0)$ & $0(0.0)$ \\
\hline Hardy-Weinberg equilibrium & 0.88 & 0.82 & 0.57 & 0.07 \\
\hline \multicolumn{5}{|l|}{ rs 231775} \\
\hline A & $142(34.8)$ & $320(34.4)$ & $189(45.2)$ & $184(34.4)$ \\
\hline G & $266(65.2)$ & $610(65.6)$ & $229(54.8)$ & $284(60.7)$ \\
\hline AA & $20(9.8)$ & $53(11.4)$ & $46(22.0)$ & $42(17.9)$ \\
\hline GA & $102(50.0)$ & $214(46)$ & $97(46.4)$ & $100(42.7)$ \\
\hline GG & $82(40.2)$ & $198(42.6)$ & $66(31.6)$ & $92(39.3)$ \\
\hline Hardy-Weinberg equilibrium & 0.15 & 0.67 & 0.36 & 0.11 \\
\hline \multicolumn{5}{|l|}{ rs3087243 } \\
\hline G & $311(76.6)$ & $750(80.3)$ & $314(74.4)$ & $349(75.5)$ \\
\hline A & $95(23.4)$ & $184(19.7)$ & $108(25.6)$ & $113(24.5)$ \\
\hline GG & $116(57.1)$ & $301(64.5)$ & $121(64.5)$ & $134(58.0)$ \\
\hline GA & $79(38.9)$ & $148(31.7)$ & $72(34.1)$ & $81(35.1)$ \\
\hline AA & $8(3.9)$ & $18(3.9)$ & $18(8.5)$ & $16(6.9)$ \\
\hline Hardy-Weinberg equilibrium & 0.22 & 0.97 & 0.13 & 0.44 \\
\hline
\end{tabular}

All groups conformed to the Hardy-Weinberg equilibrium: P>0.05. Clear, HBV clearance group; CHB, chronic active hepatitis B group; LC, HBV-related liver cirrhosis group; HCC, HBV-related hepatocellular carcinoma group. SNPs, single nucleotide polymorphisms.

regression, the difference remained significant $(\mathrm{P}=0.009$; $\mathrm{OR}=1.659$ and $95 \% \mathrm{CI}=1.137-2.421)$. At SNP site rs3087243, compared with the $\mathrm{CHB}$ group, the allele distributions revealed significant differences in the LC and HCC groups $(\mathrm{P}=0.015$ and 0.041 , respectively). However, no differences were evident following the adjustment for age and gender. Although there was no difference between the CHB and HCC groups at the SNPs rs231775 and rs3087243 following adjustment for age and gender, a trend for the correlation was observed between the polymorphisms and HCC susceptibility. The present study found that subjects with an A allele of the two polymorphisms appeared to have a greater susceptibility to HBV-related LC and HCC compared with those with a G allele.

According to the clinical considerations, LC and HCC could be lumped together since they are involved in different steps in HBV progression. In the present study, these two HBV infection populations were combined into one group by using the CHB group as the reference. At the SNP site rs231775, a significant difference was found, not only in the allele frequencies $(\mathrm{P}<0.05)$, but also in the genotype distributions $(\mathrm{P}<0.05)$ when the combined group ( $\mathrm{LC}+\mathrm{HCC}$ ) was compared with the CHB group $(\mathrm{P}=0.049, \mathrm{OR}=1.353$ and $95 \% \mathrm{CI}=1.001-1.829)$. However, for the SNP site rs3087243, the significant difference only appeared in the $\chi^{2}$ test for allele $(\mathrm{P}=0.007)$ and genotype distribution ( $\mathrm{P}=0.017$; data not shown). Although they were adjusted for age and gender and analysed by unconditional binary logistic regression, the difference in the $\mathrm{CHB}$ and the combined group (LC+HCC) was not significant in the site rs3087243, and a trend $(\mathrm{OR}=1.224$ and $\mathrm{CI}=0.904-1.656))$ was still observed. From these data, the subjects with A allele appeared to have a greater susceptibility to HBV progression compared with those with G allele in the two CTLA-4 polymorphisms, in particular in the rs231775. In addition, no association of the CTLA-4 polymorphism rs5742909 was found with HBV progression.

Associations of the CTLA-4 polymorphisms with viral persistence. According to the clinical considerations of this study and our previous study (6), CHB and LC could be lumped together, since both of them were chronic HBV carriers. The populations of the $\mathrm{CHB}$ and $\mathrm{LC}$ were combined in a similar manner to the HBV persistence group by using the clear group as the reference. Following a series of statistical analyses, the associations of the CTLA-4 polymorphisms with viral persistence were noted only at the SNP site rs5742909 of these three SNPs (Table III). In the HBV persistence group (including CHB and LC), the proportions of the $\mathrm{C}$ and $\mathrm{T}$ alleles were 89.5 and $10.5 \%$, respectively, which were significantly different from those observed in the clear group $(\mathrm{P}=0.013)$. Following adjustment for age and gender and analysis by unconditional binary logistic regression, the statistical level remained significant $(\mathrm{P}=0.012, \mathrm{OR}=1.694$ and $95 \% \mathrm{CI}=1.124-2.553)$ compared with the clear group under the best-fitting model (dominant model). In addition, under the additive model, the frequencies of the $\mathrm{C} / \mathrm{T}$ and $\mathrm{T} / \mathrm{T}$ genotypes in $\mathrm{HBV}$ persistence patients were higher compared with those in the clear subjects 
Table V. Associations of the three SNPs (rs5742909, rs231775 and rs3087243) with HBV infection progression and clearance in the Han Chinese populations (recessive and additive models).

\begin{tabular}{|c|c|c|c|c|c|c|}
\hline \multirow[b]{2}{*}{ SNP ID } & \multirow[b]{2}{*}{ Group } & \multicolumn{2}{|c|}{ Recessive model } & \multicolumn{3}{|c|}{ Additive model } \\
\hline & & P-value & OR $(95 \% \mathrm{CI})$ & Genotypes & P-value & OR $(95 \% \mathrm{CI})$ \\
\hline \multirow[t]{4}{*}{ rs5742909 } & & $\mathrm{CC}+\mathrm{CT}$ vs TT & $\mathrm{CC}+\mathrm{CT}$ vs TT & $\mathrm{CC} / \mathrm{CT} / \mathrm{TT}$ & & $\mathrm{CC} / \mathrm{CT} / \mathrm{TT}$ \\
\hline & Clear & Ref. & Ref. & Ref. & & Ref. \\
\hline & $\mathrm{CHB}+\mathrm{LC}$ & 0.25 & $2.412,(0.537,10.824)$ & (CC vs. CT) & 0.022 & $1.636,(1.074,2.553)$ \\
\hline & & & & (CC vs. TT) & 0.196 & $2.695,(0.599,12.131)$ \\
\hline \multirow[t]{6}{*}{ rs231775 } & & GG+GA vs. AA & GG+GA vs. AA & GG/GA/AA & & GG/GA/AA \\
\hline & $\mathrm{CHB}$ & Ref. & Ref. & Ref. & & Ref. \\
\hline & $\mathrm{LC}$ & 0.017 & $1.78(1.111-2.852)$ & (GG vs.GA) & $\mathrm{P} 1=0.054$ & 1.487 (0.993-2.226); \\
\hline & & & & (GG vs.AA) & $\mathrm{P} 1=0.003$ & $2.212(1.310-3.735)$ \\
\hline & $\mathrm{HCC}+\mathrm{LC}$ & 0.017 & $1.78(1.111-2.852)$ & (GG vs. GA) & $\mathrm{P} 2=0.172$ & $1.252(0.907-1.728)$ \\
\hline & & & & (GG vs. AA) & $\mathrm{P} 2=0.022$ & $1.673(1.079-2.595)$ \\
\hline \multirow[t]{6}{*}{ rs3087243 } & & GG+GA vs. AA & GG+GA vs. AA & GG/GA/AA & & GG/GA/AA \\
\hline & $\mathrm{CHB}$ & Ref. & Ref. & Ref. & & Ref. \\
\hline & $\mathrm{LC}$ & 0.18 & $1.667(0.789-3.519)$ & (GG vs. GA) & $\mathrm{P} 1=0.432$ & $1.169(0.791-1.728)$ \\
\hline & & & & (GG vs. AA) & $\mathrm{P} 1=0.146$ & $1.757(0.822-3.754)$ \\
\hline & $\mathrm{LC}+\mathrm{HCC}$ & 0.303 & $1.410(0.734-2.709)$ & (GG vs. GA) & $\mathrm{P} 2=0.427$ & $1.138(0.827-1.568)$ \\
\hline & & & & (GG vs. AA) & $\mathrm{P} 2=0.251$ & $1.474(0.760-2.858)$ \\
\hline
\end{tabular}

P-value is for Pearson's $\chi^{2}$ test. P1, LC vs. CHB; P2, LC+HCC vs. CHB. P1 and P2 are in the genotype ratios of GG/GA and GG/AA. The P-values, odds ratios (ORs), and 95\% confidence intervals (CIs) were calculated on the basis of the binary logistic regression analysis, adjusted for gender and age. SNPs, single-nucleotide polymorphisms.

Table VI. Results of the association test for the three SNPs haplotypes in the Han Chinese populations.

\begin{tabular}{|c|c|c|c|c|c|c|c|c|}
\hline Haplotype/SNP & $-318 \mathrm{C}>\mathrm{T}$ & $+49 \mathrm{~A}>\mathrm{G}$ & $+6230 \mathrm{G}>\mathrm{A}$ & $\begin{array}{c}\text { Clear } \\
(2 n=400)\end{array}$ & $\begin{array}{c}\mathrm{CH} \\
(2 \mathrm{n}=928)\end{array}$ & $\begin{array}{c}\mathrm{LC} \\
(2 \mathrm{n}=404)\end{array}$ & $\begin{array}{c}\mathrm{CH}+\mathrm{LC} \\
(2 \mathrm{n}=1332)\end{array}$ & $\begin{array}{l}\mathrm{HCC}+\mathrm{LC} \\
(2 \mathrm{n}=852)\end{array}$ \\
\hline 1 & $\mathrm{C}$ & G & $\mathrm{G}$ & $261(65.2)$ & $609(65.6)$ & $219(54.3)$ & $828(62.6)$ & $491(59.9)$ \\
\hline 2 & $\mathrm{C}$ & $\mathrm{A}$ & A & $93(23.3)$ & $186(20.0)$ & $103(25.4)$ & 289 (21.9) & $211(25.7)$ \\
\hline 3 & $\mathrm{~T}$ & A & $\mathrm{G}$ & $46(11.5)$ & $133(14.3)$ & $72(17.9)$ & $205(15.5)$ & $118(14.4)$ \\
\hline $\mathrm{P} 1-$ value $^{\mathrm{a}}$ & & & & Ref. & 0.283 & 0.102 & 0.849 & \\
\hline OR $(95 \% \mathrm{CI})$ & & & & 1 & $\begin{array}{c}0.854 \\
(0.640-1.139)\end{array}$ & $\begin{array}{c}1.320 \\
(0.946-1.841)\end{array}$ & $\begin{array}{c}0.974 \\
(0.742-1.279)\end{array}$ & \\
\hline P2-value ${ }^{a}$ & & & & Ref. & 0.246 & 0.003 & 0.054 & \\
\hline OR $(95 \% \mathrm{CI})$ & & & & 1 & $\begin{array}{c}1.246 \\
(0.861-1.778)\end{array}$ & $\begin{array}{c}1.865 \\
(1.236-2.814)\end{array}$ & $\begin{array}{c}1.406 \\
(0.992-1.993)\end{array}$ & \\
\hline$P 1-$ value $^{b}$ & & & & & Ref. & 0.003 & & 0.004 \\
\hline OR $(95 \% \mathrm{CI})$ & & & & & 1 & $\begin{array}{c}1.546 \\
(1.161-2.058)\end{array}$ & & $\begin{array}{c}1.403 \\
(1.114-1.767)\end{array}$ \\
\hline P2-value ${ }^{b}$ & & & & & Ref. & 0.014 & & 0.512 \\
\hline OR $(95 \% \mathrm{CI})$ & & & & & 1 & $\begin{array}{c}1.503 \\
(1.085-2.082)\end{array}$ & & $\begin{array}{c}1.096 \\
(0.833-1.443)\end{array}$ \\
\hline
\end{tabular}

P1-value: CGG vs. CAA; P2-value: CGG vs. TAG. P1 and P2 represent P-value calculated on the binary logistic regression analysis and adjusted for sex and age. Haplotypes with frequencies $<0.05$ were not considered. ${ }^{a}$ Three SNPs haplotypes C-G-G, C-A-A, T-A-G in the clear group compared with those in the

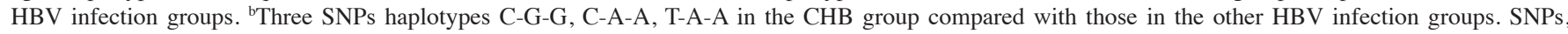
single-nucleotide polymorphisms.

(25.53 vs. $19 \%$ and 2.7 vs. $1 \%$, respectively). Their ORs reached $1.636(95 \% \mathrm{CI}=1.074-2.492$ and $\mathrm{P}=0.022)$ and 2.695 (95\% $\mathrm{CI}=0.599-12.131$ and $\mathrm{P}=0.196$ ) compared with the $\mathrm{C} / \mathrm{C}$ genotype (Table V). These results indicated that the $\mathrm{T} / \mathrm{T}$ and $\mathrm{C} / \mathrm{T}$ genotypes and $\mathrm{T}$ allele of the polymorphism rs5742909 may increase the risk of HBV persistence. 


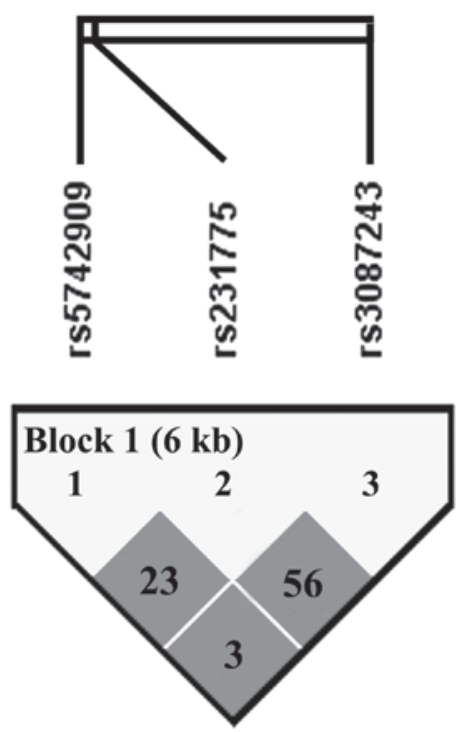

Figure 1. Linkage disequilibrium analysis of the SNPs rs5742909, rs231775 and rs3087243 in HBV clearance population $(n=200)$ generated by HaploView 4.2 software. SNPs, single-nucleotide polymorphisms; HBV, hepatitis B virus.

Results of the haplotype analysis. In order to understand the contributions of these loci to the HBV susceptibility, three-locus haplotypes were constructed for the SNPs rs5742909, rs231775 and rs3087243 (Table VI). Pairwise LD analyses (Fig. 1) were performed using all the individuals from the clear group. Results of the analyses revealed that the SNPs rs5742909, rs 231775 and rs3087243 were in $L D$ with each other $\left(D^{\prime}=1\right.$, $r^{2}=0.233$ between rs5742909 and $r s 231775 ; D^{\prime}=1, r^{2}=0.564$ between $r$ s 231775 and $r s 3087243 ; D^{\prime}=1, r^{2}=0.035$ between rs5742909 and rs3087243). In order to derive HBV infection-specific haplotypes, haplotypes with frequencies $<0.05$ were not considered and three haplotypes were observed. When a protective haplotype C-G-G was selected as a baseline, haplotypes C-A-A and T-A-G exhibited an increased susceptibility to progressed hepatitis and the haplotype T-A-G revealed an increased risk for viral persistence (P-value and OR are shown in Table VI). Three-loci haplotyping was performed only for the subjects with complete genotyping.

\section{Discussion}

The outcomes of the HBV infection vary according to the vigor of the immune response, a process that is regulated by a number of molecules, including the cell surface receptor CTLA-4 (25). The CTLA- 4 gene is expressed by T-lymphocytes and functions as an inhibitory receptor, acting as a negative regulator of T-cell responses (31). Mohammad Alizadeh et al (26) and Schott et al (27) demonstrated a significant association between the genotypes or alleles of the mutation rs5742909 and the susceptibility to chronic hepatitis B. In their studies, $\mathrm{Gu}$ et al and $\mathrm{Hu}$ et al demonstrated that the SNP site rs 231775 was associated with HCC $(23,29)$. However, Gu et al only identified the association in a male Chinese population and $\mathrm{Hu}$ et $a l$ included HCC subjects with a virus infection as well as with HBV. Thio et al (25) reported that presence of allele $+6230 \mathrm{~A}$ in the 3'UTR of the CTLA4 gene (at SNP site rs3087243) was suspected to have viral persistence and that allele $+49 \mathrm{G}$ (at SNP site rs231775) was detected more often in individuals who recovered from HBV infection. Although the association between various outcomes of HBV infection and the CTLA-4 gene has become increasingly evident $(24,28)$, their diagnosis criteria were not completely equal and the ethnic background difference should be considered. Different results are therefore likely to arise with different diagnosis criteria and ethic backgrounds although the control and case groups are similar.

In the analysis of the present study, three SNPs sites (rs5742909, rs231775 and rs3087243) in the gene CTLA-4 were confirmed to be significantly associated with HBV infection. Additionally, CTLA-4 haplotypes are significant determinants of the HBV infection in the Hubei Han Chinese population. Haplotypes containing the $+49 \mathrm{G}$ allele were protective against HBV progression and viral persistence. Since these haplotypes may alter the ability of CTLA-4 to downregulate the immune response, these data indicated that the vigor of counter-regulatory mechanisms contributes to HBV infection. Although the present study may not have indicated that the genotypes distribution in all these three sites (rs5742909, rs231775 and rs3087243) was significantly different between the control and case groups, the frequencies of susceptible alleles were similar compared with those in other Chinese populations. Thus, it may be confirmed that the polymorphisms of the CTLA-4 gene play a crucial role in HBV progression and viral persistence in the Hubei Han Chinese population.

Following HBV infection, the inflammatory immune response of the host induces hepatocellular damage and is followed by the pathogenesis of liver cirrhosis and cancer (32). Liver cancer arises most frequently in the setting of chronic liver inflammation (33). In the present study, the allele $+49 \mathrm{~A}$ was identified as a risk factor for HBV progression while the mutation allele $+49 \mathrm{G}$ may be protective against $\mathrm{HBV}$ progression. Inherited changes or SNPs in CTLA-4 expression that presumably alter T-cell self-reactivity have been found to be associated with autoimmune disorders $(10,34,35)$ including autoimmune liver disease (36-39). The $A \rightarrow G$ mutation which exists at position +49 in exon 1 (rs231775) leads to a non-synonymous amino acid change from threonine to alanine, thus changing the polarity of the amino acid and potentially altering the function of the protein. The $+49 \mathrm{~A}$ allele has been associated with a decreased risk for diseases resulting from a downregulated vigorous immune response (36,40-42). Similarly, in an earlier study, the allele $+49 \mathrm{G}$ was also associated with improved clearance of an $\mathrm{HCV}$ infection resulting from $\alpha$-interferon-based therapy (43). Lymphocytes from donors carrying $+49 \mathrm{G}$ appear to express less CTLA- 4 on their surfaces, proliferate more under conditions of suboptimal activation and exhibit less CTLA-4-mediated inhibition of the T-cell responses (44).

The SNP rs5742909 is an $\mathrm{A} \rightarrow \mathrm{G}$ mutation in the promoter region at position -318 of the CTLA- 4 gene. It has been demonstrated that the $-318 \mathrm{~T}$ allele of CTLA-4 may result in increased levels of CTLA-4 mRNA compared with the $-318 \mathrm{C} /-318 \mathrm{C}$ homozygote (45) and an increased expression of CTLA-4 following activation (46). Although in the present study, only the association between the mutation and viral persistence was observed, the haplotype containing $-318 \mathrm{C}$ or $-318 \mathrm{~T}$ is associated with viral persistence and HBV progres- 
sion, as mentioned in previous studies $(24,27)$. In addition, individuals with the allele $+6230 \mathrm{~A}$ in the 3 ' UTR (at the site rs3087243) were also found to be more likely to have HBV progression. Ueda et al (10) reported that the SNP site rs3087243 determines the levels of the soluble isoform of CTLA-4 (sCTLA-4), which has been demonstrated in vitro to inhibit T-cell proliferation. This may partially account for the association of this haplotype containing the $+6230 \mathrm{~A}$ allele with HBV progression.

In the presence of two functional polymorphisms on the same LD block, when the predisposing allele of one is in LD with the protective allele of the other, the genetic effects of individual SNPs are likely to be blunted by an increase in the frequency of haplotypes that carry one predisposing and one protective allele (47). Chistiakov et al (48) suggested that whether the haplotype are likely to be susceptible, protective or neutral depends on a ratio between predisposing and protective alleles constituting a haplotype and an interaction between their functional significance and strength of their functional effects. Therefore, it is possible that the effects of the three SNPs in chronic HBV patients involved in the present study may be due to the linkage to each other, in particular to the linkage to $+49 \mathrm{~A} / \mathrm{G}$.

In summary, in the present case-control study, the A allele of the rs231775 and rs3087243 SNPs sites in CTLA-4 was confirmed to be significantly associated with HBV progression in the Han Chinese population, and allele T in rs5742909 revealed a strong risk effect on viral persistence. Although HBV disease is not determined solely by genetic factors, the experimental results offer the foundation for further study of genetic variations in CTLA-4 for the prevention and therapy of chronic HBV infection. However, following adjustment for age and gender, the association among the three SNPs and the HBV-related HCC, excluding the ( $\mathrm{LC}+\mathrm{HCC}$ ) group, was not observed. This may be due to the difference in criteria and ethnic background. Future investigations with a larger sample size, multi-center study and functional studies in this gene are required to confirm the results of the present study.

\section{Acknowledgements}

This study was financially supported by the National Basic Research Program of China (no. 2007CB512903) and the National Natural Science Foundation of China (no. 81101824 and 30872237).

\section{References}

1. Guo $\mathrm{XC}$ and Wu YQ: A review: progress of prevention and control on viral hepatitis in China. Biomed Environ Sci 12: 227-232, 1999.

2. Ganem D and Prince AM: Hepatitis B virus infection - natural history and clinical consequences. N Engl J Med 350: 1118-1129, 2004.

3. Thursz M: Genetic susceptibility in chronic viral hepatitis. Antiviral Res 52: 113-116, 2001.

4. Harnprasopwat R, Ha D, Toyoshima T, Lodish H, Tojo A and Kotani A: Alteration of processing induced by a single nucleotide polymorphism in pri-miR-126. Biochem Biophys Res Commun 399: 117-122, 2010.

5. Li J, Yang D, He Y, et al: Associations of HLA-DP variants with hepatitis B virus infection in southern and northern Han Chinese populations: a multicenter case-control study. PLoS One 6: e24221, 2011.
6. He XX, Chang Y, Jiang HJ, et al: Persistent effect of IFNAR-1 genetic polymorphism on the long-term pathogenesis of chronic HBV infection. Viral Immunol 23: 251-257, 2010.

7. Liu L, Li J, Yao J, et al: A genome-wide association study with DNA pooling identifies the variant rs11866328 in the GRIN2A gene that affects disease progression of chronic HBV infection. Viral Immunol 24: 397-402, 2011.

8. Liu L, Yao J, Li J, et al: Effects of variant rs346473 in ARHGAP24 gene on disease progression of HBV infection in Han Chinese population. J Huazhong Univ Sci Technolog Med Sci 31: 482-487, 2011.

9. Szmaragd C, Nichols RA and Balloux F: A novel approach to characterise pathogen candidate genetic polymorphisms involved in clinical outcome. Infect Genet Evol 6: 38-45, 2006.

10. Ueda H, Howson JM, Esposito L, et al: Association of the T-cell regulatory gene CTLA4 with susceptibility to autoimmune disease. Nature 423: 506-511, 2003.

11. Carreno BM, Bennett F, Chau TA, et al: CTLA-4 (CD152) can inhibit $\mathrm{T}$ cell activation by two different mechanisms depending on its level of cell surface expression. J Immunol 165: 1352-1356, 2000.

12. Kuchroo VK, Das MP, Brown JA, et al: B7-1 and B7-2 costimulatory molecules activate differentially the Th1/Th2 developmental pathways: application to autoimmune disease therapy. Cell 80: 707-718, 1995.

13. Dariavach P, Mattéi MG, Golstein P and Lefranc MP: Human Ig superfamily CTLA-4 gene: chromosomal localization and identity of protein sequence between murine and human CTLA-4 cytoplasmic domains. Eur J Immunol 18: 1901-1905, 1988.

14. Leach DR, Krummel MF and Allison JP: Enhancement of antitumor immunity by CTLA-4 blockade. Science 271: 1734-1736, 1996.

15. Hellings PW, Vandenberghe P, Kasran A, et al: Blockade of CTLA-4 enhances allergic sensitization and eosinophilic airway inflammation in genetically predisposed mice. Eur J Immunol 32: 585-594, 2002

16. Karandikar NJ, Vanderlugt CL, Walunas TL, Miller SD and Bluestone JA: CTLA-4: a negative regulator of autoimmune disease. J Exp Med 184: 783-788, 1996.

17. Kirman J, McCoy K, Hook S, et al: CTLA-4 blockade enhances the immune response induced by mycobacterial infection but does not lead to increased protection. Infect Immun 67: 3786-3792, 1999.

18. Espenschied J, Lamont J, Longmate J, et al: CTLA-4 blockade enhances the therapeutic effect of an attenuated poxvirus vaccine targeting p53 in an established murine tumor model. J Immunol 170: 3401-3407, 2003.

19. Scheipers P and Reiser H: Fas-independent death of activated CD4(+) T lymphocytes induced by CTLA-4 crosslinking. Proc Natl Acad Sci U S A 95: 10083-10088, 1998.

20. Ohta A, Sekimoto M, Sato M, et al: Indispensable role for TNF-alpha and IFN-gamma at the effector phase of liver injury mediated by Th1 cells specific to hepatitis B virus surface antigen. J Immunol 165: 956-961, 2000.

21. Stoop JN, Woltman AM, Biesta PJ, et al: Tumor necrosis factor alpha inhibits the suppressive effect of regulatory $\mathrm{T}$ cells on the hepatitis B virus-specific immune response. Hepatology 46: 699-705, 2007.

22. Han Q, Duan S, Zhang G, et al: Associations between cytotoxic T lymphocyte-associated antigen-4 polymorphisms and serum tumor necrosis factor- $\alpha$ and interferon- $\gamma$ levels in patients with chronic hepatitis B virus infection. Inflamm Res 60, 1071-1078, 2011.

23. Hu L, Liu J, Chen X, et al: CTLA-4 gene polymorphism +49 A/G contributes to genetic susceptibility to two infection-related cancers-hepatocellular carcinoma and cervical cancer. Hum Immunol 71: 888-891, 2010.

24. Duan S, Zhang G,Han Q, et al: CTLA-4 exon 1+49 polymorphism alone and in a haplotype with -318 promoter polymorphism may confer susceptibility to chronic HBV infection in Chinese Han patients. Mol Biol Rep 38, 5125-5132, 2011.

25. Thio CL, Mosbruger TL, Kaslow RA, et al: Cytotoxic T-lymphocyte antigen 4 gene and recovery from hepatitis B virus infection. J Virol 78: 11258-11262, 2004.

26. Mohammad Alizadeh AH, Hajilooi M, Ranjbar M, Fallahian F and Mousavi SM: Cytotoxic T-lymphocyte antigen 4 gene polymorphisms and susceptibility to chronic hepatitis B. World J Gastroenterol 12: 630-635, 2006.

27. Schott E, Witt H, Pascu M, et al: Association of CTLA4 single nucleotide polymorphisms with viral but not autoimmune liver disease. Eur J Gastroenterol Hepatol 19: 947-951, 2007. 
28. Chen DQ, Zeng Y, Zhou J, et al: Association of candidate susceptible loci with chronic infection with hepatitis B virus in a Chinese population. J Med Virol 82: 371-378, 2010.

29. Gu X, Qi P, Zhou F, et al: $+49 \mathrm{G}>$ A polymorphism in the cytotoxic T-lymphocyte antigen- 4 gene increases susceptibility to hepatitis B-related hepatocellular carcinoma in a male Chinese population. Hum Immunol 71: 83-87, 2010.

30. Excoffier L and Lischer HE: Arlequin suite ver 3.5: a new series of programs to perform population genetics analyses under Linux and Windows. Mol Ecol Resour 10: 564-567, 2010.

31. Shevach EM: $\mathrm{CD}^{+}{ }^{+} \mathrm{CD} 25^{+}$suppressor T cells: more questions than answers. Nat Rev Immunol 2: 389-400, 2002.

32. Fattovich G, Bortolotti F and Donato F: Natural history of chronic hepatitis B: special emphasis on disease progression and prognostic factors. J Hepatol 48: 335-352, 2008.

33. Yang HI, Lu SN, Liaw YF, et al: Hepatitis B e antigen and the risk of hepatocellular carcinoma. N Engl J Med 347: 168-174, 2002.

34. Aguilar F, Torres B, Sánchez-Román J, Núñez-Roldán A and González-Escribano MF: CTLA4 polymorphism in Spanish patients with systemic lupus erythematosus. Hum Immunol 64: 936-940, 2003.

35. Parks CG, Hudson LL, Cooper GS, et al: CTLA-4 gene polymorphisms and systemic lupus erythematosus in a population-based study of whites and African-Americans in the southeastern United States. Lupus 13: 784-791, 2004.

36. Agarwal K, Czaja AJ, Jones DE and Donaldson PT: Cytotoxic $\mathrm{T}$ lymphocyte antigen-4 (CTLA-4) gene polymorphisms and susceptibility to type 1 autoimmune hepatitis. Hepatology 31 : $49-53,2000$

37. Agarwal K, Jones DE, Daly AK, et al: CTLA-4 gene polymorphism confers susceptibility to primary biliary cirrhosis J Hepatol 32: 538-541, 2000.

38. Djilali-Saiah I, Ouellette P, Caillat-Zucman S, Debray D, Kohn JI and Alvarez F: CTLA-4/CD 28 region polymorphisms in children from families with autoimmune hepatitis. Hum Immunol 62: 1356-1362, 2001.

39. Fan LY, Tu XQ, Cheng QB, et al: Cytotoxic T lymphocyte associated antigen-4 gene polymorphisms confer susceptibility to primary biliary cirrhosis and autoimmune hepatitis in Chinese population. World J Gastroenterol 10: 3056-3059, 2004.
40. Ahmed S, Ihara K, Kanemitsu S, et al: Association of CTLA-4 but not CD28 gene polymorphisms with systemic lupus erythematosus in the Japanese population. Rheumatology (Oxford) 40: 662-667, 2001

41. Ihara K, Ahmed S, Nakao F, et al: Association studies of CTLA-4, CD28, and ICOS gene polymorphisms with type 1 diabetes in the Japanese population. Immunogenetics 53: 447-454, 2001.

42. Kouki T, Sawai Y, Gardine CA, Fisfalen ME, Alegre ML and DeGroot LJ: CTLA-4 gene polymorphism at position 49 in exon 1 reduces the inhibitory function of CTLA-4 and contributes to the pathogenesis of Graves' disease. J Immunol 165: 6606-6611, 2000.

43. Yee LJ, Perez KA, Tang J, van Leeuwen DJ and Kaslow RA: Association of CTLA4 polymorphisms with sustained response to interferon and ribavirin therapy for chronic hepatitis $\mathrm{C}$ virus infection. J Infect Dis 187: 1264-1271, 2003.

44. Mäurer M, Loserth S, Kolb-Mäurer A, et al: A polymorphism in the human cytotoxic T-lymphocyte antigen 4 ( CTLA4) gene (exon $1+49$ ) alters T-cell activation. Immunogenetics 54: 1-8, 2002.

45. Wang XB, Zhao X, Giscombe R and Lefvert AK: A CTLA-4 gene polymorphism at position -318 in the promoter region affects the expression of protein. Genes Immun 3: 233-234, 2002.

46. Ligers A, Teleshova N, Masterman T, Huang WX and Hillert J: CTLA-4 gene expression is influenced by promoter and exon 1 polymorphisms. Genes Immun 2: 145-152, 2001.

47. Anjos SM, Tessier MC and Polychronakos C: Association of the cytotoxic T lymphocyte-associated antigen 4 gene with type 1 diabetes: evidence for independent effects of two polymorphisms on the same haplotype block. J Clin Endocrinol Metab 89: 6257-6265, 2004

48. Chistiakov DA, Savost'anov KV, Turakulov RI, Efremov IA and Demurov LM: Genetic analysis and functional evaluation of the $\mathrm{C} / \mathrm{T}(-318)$ and $\mathrm{A} / \mathrm{G}(-1661)$ polymorphisms of the CTLA-4 gene in patients affected with Graves' disease. Clin Immunol 118: 233-242, 2006. 